\title{
Epidemiology and Risk Factors for Cataract
}

\author{
J. J. HARDING and R. van HEYNINGEN \\ Oxford
}

\begin{abstract}
Summary
Cataract is the major cause of blindness worldwide. It is a greater problem in third world countries than in the West and several attempts have been made to explain the excess in these countries. This paper provides an overview of the literature especially on studies designed to identify risk factors for cataract. There is an association between poverty and cataract and, more specifically, between cataract and a history of severe diarrhoea-dehydration. Recent results from a case-controlled study of cataract in Oxford are also presented with the quantitation of risks associated with a number of factors including diarrhoea, renal failure and diabetes. In this study an apparently protective effect of aspirin, paracetamol and similar drugs was observed. This protective effect applies to the risk associated with diabetes.
\end{abstract}

Cataract is responsible for more clinic visits and more new patients than any other eye disease in this country. ${ }^{1}$ Almost two thirds of new patients listed for surgery are to have cataract operations. Cataract is a much greater problem in the third world where it is much more common and is of earlier onset. Cataract accounts for 55 per cent of the blindness in India, that is about 5 million blind in that one country, ${ }^{2}$ and over 60 per cent of blindness in Nepal. ${ }^{3}$ It is not surprising that sunlight was proposed as the cause of not only the excess cataract in tropical countries but also of much cataract even in more temperate areas. This hypothesis was tested fifty years ago by Wright who inspected the lenses of 4,000 outdoor labourers in two areas of India, one hot, dry and cloudless, and the other more cloudy. ${ }^{4} \mathrm{He}$ found cataract more common in the cloudier area and concluded that sunlight is probably not an important factor in determining the high frequency of cataract in
South India. This paper seems to have been forgotten and in the sixties interest in the sunlight hypothesis revived, specifically in relation to brown nuclear cataract, but in spite of some encouraging biochemical studies the hypothesis had at least three serious weaknesses. ${ }^{5.6}$

Firstly, the earliest change to lens proteins exposed to sunlight in vitro is a loss of tryptophan which is not found in human cataracts, not even in brown nuclear cataracts. Secondly, the sunlight-induced yellowing proceeds equally well in cortex and nucleus in vitro. Thirdly climatic droplet keratopathy, and pterygium, which are associated with sunlight, are not associated with cataract.

A survey of cataract in the Punjab ${ }^{7.8}$ indicated that various aspects of poor living conditions were associated with cataract (Table I). In other studies it appears that cataract is more common among the poorer groups of each society. In Israel the incidence of catar-

From: Nuffield Laboratory of Ophthalmology, University of Oxford, Walton Street, Oxford OX2 6AW.

Correspondence to: Dr John J. Harding, Nuffield Laboratory of Ophthalmology, University of Oxford, Walton Street, Oxford OX2 6AW.

Presented at the Annual Congress of the Ophthalmological Society of the United Kingdom, April 1987. 
Table I Some risk factors for cataract in India

\begin{tabular}{lcc}
\hline & $\begin{array}{c}\text { Relative risk } \\
\text { (odds ratio) }\end{array}$ & Reference \\
\hline Risk factor & & \\
\hline $\begin{array}{l}\text { Living on dry plains (cf } \\
\text { mountains) }\end{array}$ & 18 \\
$\begin{array}{l}\text { Living in city slums (cf } \\
\quad \text { villages) }\end{array}$ & 1.8 & 7 \\
Low caste & 3.0 & 7 \\
Widowed & 2.2 & 7 \\
Illiterate (cf high school & & \\
$\quad$ graduate) & 7.5 & 7 \\
Low consumption of: & & \\
$\quad$ beans and lentils & 2.3 & 7 \\
$\quad$ vegetables & 1.8 & 7 \\
Zero consumption of: & & \\
$\quad$ meat & 2.1 & 7 \\
$\quad$ milk & 1.6 & 7 \\
eggs & 2.4 & 7 \\
$\quad$ curd & 1.7 & 7 \\
Low height & 1.8 & 7 \\
Low weight & 1.9 & 7 \\
Low weight/height & 1.6 & 16 \\
Life-threatening diarrhoea: & & 16 \\
$\quad$ one episode & 4.1 & \\
more than one episode & 21 & \\
\hline
\end{tabular}

act is greater among oriental Jews compared to European Jews. ${ }^{9}$ In the United States the prevalence is greater among blacks compared to whites,,$^{10}$ and in Australia it is more common among Aborigines. ${ }^{11}$ In both India ${ }^{7}$ and the United States ${ }^{11}$ a lower educational attainment was associated with a greater risk of cataract. In the Indian study the comparison of illiterate subjects to high school graduates gave the highest relative risk that they found (Table I).

In 1980 I put forward the diarrhoeal

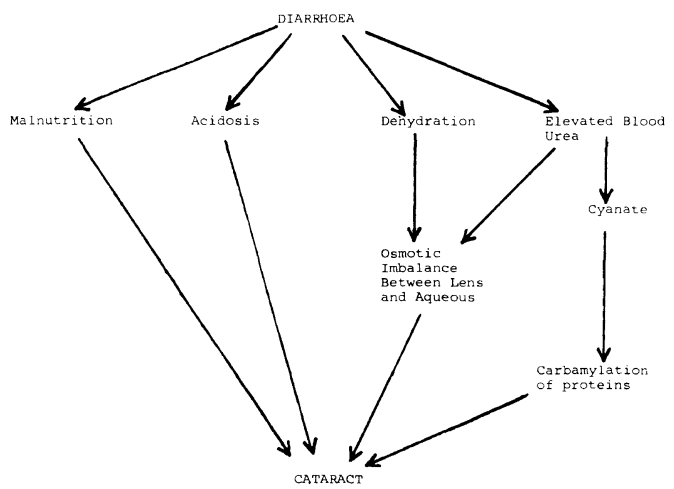

Fig. 1. Speculative scheme indicating the possible relationship between diarrhoea and cataract ${ }^{\prime \prime}$. hypothesis to account for the high prevalence of cataract in third world countries ${ }^{12.13}$ (see Fig. 1).

In the laboratory we have studied the effect of cyanate on lens proteins and on incubated lenses. Cyanate can bind to lens proteins ${ }^{1.3}$ causing them to unfold revealing buried thiol groups which form protein-protein disulphide bonds. ${ }^{14}$ Thus cyanate treatment induces changes similar to those found in human cataract. Cyanate also causes opacification of incubated rat lenses. ${ }^{15}$

Laboratory studies such as these while indicating how severe diarrhoea might lead to cataract partly through cyanate modification of protein do not test the diarrhoeal hypothesis directly. The first test came in the form of a paired case-control study of cataract patients in Raipur India. This showed that 'life-threatening diarrhoea' is a powerful risk factor for cataract (Table I), and may account for 40 per cent of the cataract in that area ${ }^{16}$ If this were true of the whole of India it would mean that cataract associated with life-threatening diarrhoea accounts for the blindness of 2 million Indians.

In the United Kingdom another case-control study in Edinburgh ${ }^{17}$ revealed rather different risk factors including diabetes, psychiatric illness, use of major tranquillizers, diuretics, alcohol, tobacco and topically applied ophthalmic drugs, hypertension and glaucoma (Table II). In addition the mean levels of plasma urea, fasting glucose and creatinine were slightly elevated in cataract patients whereas calcium, phosphate, cholesterol and albumin were lowered. The mean glucose level was raised even after known diabetics were excluded from the calculations. The distribution of plasma urea levels was bimodal in the cataract patients with a subpopulation having blood urea levels close to $10 \mathrm{mM} .{ }^{18}$ Risk factors identified in Indian and in Western populations are summarised in Tables I and II.

We have carried out a case-control study of cataract in Oxfordshire. ${ }^{20}$ Three hundred cataract patients and 609 controls were interviewed. The age-sex distribution of the controls was matched to that of the patients. We confirmed some risks previously identified including diabetes, glaucoma and use of 
Table II Some risk factors for cataract in Great Britain and the United States

\begin{tabular}{|c|c|c|}
\hline Risk factor & $\begin{array}{l}\text { Relative risk } \\
\text { (odds ratio) }\end{array}$ & Reference \\
\hline \multicolumn{3}{|l|}{ Black American (cf white } \\
\hline American) & - & 9 \\
\hline $\begin{array}{l}\text { Lower educational } \\
\text { standard }\end{array}$ & & 19 \\
\hline Diabetes & 6.2 & 17,20 \\
\hline Renal failure & 12.4 & 20 \\
\hline Glaucoma & 5.9 & 17,20 \\
\hline Hypertension & 一 & $9,17,19$ \\
\hline Cardiovascular disease & - & 17 \\
\hline Psychiatric illness & - & 17 \\
\hline Severe diarrhoea & 1.6 & 20 \\
\hline Myopia when young & 2.0 & 21 \\
\hline \multicolumn{3}{|l|}{ Low height, vital capacity } \\
\hline \multicolumn{3}{|l|}{ Use of: } \\
\hline Major tranquillisers & - & 17 \\
\hline Diuretics & - & 17 \\
\hline $\begin{array}{l}\text { Topical ophthalmic } \\
\text { drugs }\end{array}$ & - & 17 \\
\hline Steroids & 1.8 & 20 \\
\hline Alcohol & & 17 \\
\hline Cigarettes & & 17 \\
\hline \multicolumn{3}{|l|}{ High plasma: } \\
\hline $\begin{array}{l}\text { Fasting glucose (cuasal } \\
\text { glucose) }\end{array}$ & & $17(19)$ \\
\hline Urea & & 17 \\
\hline Creatinine & & 17 \\
\hline Phospholipid & & 19 \\
\hline \multicolumn{3}{|l|}{ Low plasma: } \\
\hline Calcium & & 17 \\
\hline Phosphate & & 17 \\
\hline Cholesterol & & 17 \\
\hline Albumin & & 17 \\
\hline
\end{tabular}

* Relative risks are from ref. 20.

steroids and were able to calculate relative risks for these (Table II). In addition we identified renal failure as a powerful risk factor. Severe diarrhoea, which is such a powerful risk factor in India (Table I), is a risk factor even in the Oxford population (Table II).

The relative risk for diabetes is high (Table II) and about 12 per cent of cataracts in Oxford can be attributed to this single cause. The relative risk differs between the sexes being 3.2 in males and 10.5 in females. ${ }^{21}$

The most surprising finding in the Oxford study was that in addition to finding factors that gave an enhanced risk of cataract, that is a relative risk significantly greater than unity, we also identified factors associated with a diminished risk of cataract (relative risk less than one). Consumption of 'aspirin-like analgesics' (mostly aspirin, paracetamol and ibuprofen) was associated with a halving of the risk of cataract. ${ }^{20}$ In more recent analyses we have examined individual risk factors to see whether consumption of these drugs affords any specific protection.

Aspirin-like analgesics appeared to confer a protection against cataract in those with diabetes (Table III). The relative risk in those not reporting aspirin-like analgesics is 7.5 compared to 4.7 in those who reported taking these drugs. The overall proportion of subjects reporting these drugs was the same for the diabetics (25.4 per cent) and the non-diabetics ( 26.0 per cent). We found a much greater risk in females than in males so we analysed the data for each sex separately. The aspirin-like analgesics did not provide significant protection to male diabetics but in females the relative risk of 10.5 rose to 22.4 in those not reporting analgesics (Table IV).

Table III Protection by aspirin-like analgesics* against the risk of cataract associated with diabetes

\begin{tabular}{lcc}
\hline \multicolumn{1}{c}{ Factor } & Relative risk & $P$ \\
\hline $\begin{array}{l}\text { Diabetes in all subjects } \\
\text { Diabetes in subjects report- } \\
\text { ing aspirin-like analgesics }\end{array}$ & 6.2 & $<<0.001$ \\
$\begin{array}{l}\text { Diabetes in subjects NOT } \\
\text { reporting aspirin-like } \\
\text { analgesics }\end{array}$ & 7.5 & $<0.001$ \\
$\begin{array}{l}\text { Diabetes in females } \\
\text { Diabetes in females report- } \\
\text { ing aspirin-like analgesics }\end{array}$ & 6.3 & $<0.001$ \\
$\begin{array}{l}\text { Diabetes in females NOT } \\
\text { reporting aspirin-like } \\
\text { analgesics }\end{array}$ & 22.4 & $<0.001$ \\
\hline
\end{tabular}

* Paracetamol (acetaminophen), aspirin, ibuprofen and similar drugs, naproxen, benorylate, mefenamic acid and flufenamic acid.

Table IV The risk of cataract associated with diabetes in females not reporting aspirin-like analgesics

\begin{tabular}{lrrr}
\hline & Controls & Cases & Total \\
\hline Diabetes & 2 & 22 & 24 \\
No diabetes & 216 & 106 & 322 \\
\hline Total & 218 & 128 & 346 \\
Per cent positive & 0.9 & 17.2 & \\
\hline
\end{tabular}

Chi-squared text $\mathrm{P} \ll 0.001$.

Odds ratio $=22.4(5.2$ to 97.1$)$. 
Although there were only two diabetic controls not reporting aspirin-like analgesics the chi-squared test is valid because the expected values are greater than 5 for each cell. Those reporting analgesics have decreased their relative risk to 6.3 (Table III). The 95 per cent confidence bounds of the relative risk in females not reporting aspirin-like analgesics are broad (5.2 to 97), nevertheless it appears that these drugs are associated with a powerful protective effect against cataract in female diabetics who have taken them regularly for at least four months. It is of interest that aspirinlike analgesics were reported by 32 per cent of all females and 19 per cent of all males in the study. Possible mechanisms for the protective effect of aspirin against cataract have been discussed previously, but it is difficult to find a mechanism that can encompass the known actions of aspirin, paracetamol and ibuprofen. The laboratory studies of aspirin led to the suggestion that acetylation of lens proteins by aspirin protected them against attack by chemical agents including cyanate, glucose, glucose 6-phosphate and other sugars. ${ }^{15}$ However, paracetamol is not known to acetylate proteins and ibuprofen and the other acidic analgesics do not have acetyl groups to transfer, so an alternative explanation must be sought. It might be thought that aspirin and ibuprofen were protecting by inhibiting prostaglandin synthesis but that explanation would exclude paracetamol which is a feeble inhibitor of cyclo-oxygenase. On the other hand, indomethacin, a powerful inhibitor of prostaglandin synthesis, is not associated with the protection against cataract being reported by 3.1 per cent of controls and 3.3 per cent of cases. ${ }^{20}$

Another possible mechanism for the apparent protection against cataract by aspirin-like analgesics is that they act by lowering blood glucose levels. ${ }^{20}$ Aspirin-like analgesics lower fasting blood glucose levels and improve glucose tolerance in diabetics and non-diabetics by stimulating the insulin response to glucose.

The suggestion that aspirin-like analgesics could act in this way is strengthened by the specific protection against cataract at least in females with diabetes (Tables III and IV). In non-diabetics in this age range (50-79) the age-related decrease in glucose tolerance may be minimised by aspirin-like analgesics.

In studies of risk factors for disease it is important not only to assess the enhancement of risk by a risk factor but also to calculate the proportion of the disease that would in theory be eliminated were the risk factor itself eliminated. This proportion is the population attributable risk per cent and its calculation assumes a causal relationship.

The population attributable risk per cent indicates that diabetes may be responsible for about 12 per cent of cataract extractions in Oxford. The aspirin-like analgesics are taken by 30 per cent of controls and appear to halve the risk of cataract. ${ }^{20}$ Turning this round to treat NOT reporting an aspirin-like analgesic as a risk factor, produces a relative risk of 2.1 experienced by 70 per cent of the population. It can be calculated that the population attributable risk associated with NOT reporting aspirin-like analgesics is 43 per cent. This is much greater than the risk attributable to diabetes so the aspirin-like analgesics must provide a broader protection which will no doubt include totally distinct insults to the lens such as cyanate and corticosteroids, but could also include protection against impaired glucose control that falls short of current definitions of diabetes. Moderately elevated fasting blood glucose levels in non-diabetics appeared as a risk factor for cataract in Edinburgh. ${ }^{17}$ It has been reported that 44 per cent of cataract patients have an abnormal glucose tolerance curve. ${ }^{22}$ These reports lead to the view that a modest elevation of glucose over many years is damaging to the lens. This slowly accumulating damage is probably not acting through an osmotic effect and is much more likely to be caused by non-enzymic glycosylation known to occur in many tissues that are the sites of diabetic sequelae. ${ }^{2.3}$

\section{References}

${ }^{1}$ Shaw DE, Gibson JM, Rosenthal AR: A year in a general ophthalmic out patient department in England. Arch Ophthalmol 1986, 104: 1843-6.

2 Agarwal LP: National Programme for prevention of visual impairment and control of blindness in India. New Delhi. Ministry of Health and Family Welfare 1978.

${ }^{3}$ Brilliant LB, Pokhrel RP, Grasset NC, Lepkowski KM, Kolstad A, Hawks W, Pararajasegaram R, Brilliant GE, Gilbert S, Shrestha SR and Kuo J: 
Epidemiology of blindness in Nepal. Bull WHO 1985, 63: 375-86.

${ }^{4}$ Wright RE: The possible influence of solar radiation on the production of cataract in certain districts of southern India: a preliminary investigation. Indian J Med Res 1937, 24: 917-20.

${ }^{5}$ Dilley KJ and Pirie A: Changes to the proteins of the human lens nucleus in cataract. Exp Eye Res 1974, 19: 59-72.

${ }^{6}$ Harding JJ and Crabbe MJC: The lens: development, proteins, metabolism and cataract. In Davson $\mathrm{H}$ ed The Eye 3rd edition, Vol I B. London: Academic Press 1984: 207-492.

${ }^{7}$ Chatterjee A, Milton RC and Thyle S: Cataract prevalence and aetiology in Punjab. $\mathrm{Br} J$ Ophthalmol 1982, 66: 35-42.

${ }^{8}$ Chatterjee A: Cataract in Punjab. Ciba Symp 1973, 19: $265-79$.

${ }^{9}$ Halevi HS and Landau J: Hospitalized senile cataract in different Jewish communities in Israel. Brit J Ophthalmol 1962, 46: 285-90.

${ }^{10}$ Klein BE and Klein R: Cataracts and macular degeneration in older Americans. Arch Ophthalmol 1982, 100: 571-3.

${ }^{11}$ Hollows FC, Waterford J, Jones D, Moran D, Buzzacott T, McGrath P, Cook P: The National Trachoma and Eye Health Programme Report. Royal Australian College of Ophthalmologists 1980.

12 Harding JJ: Possible causes of the unfolding of proteins in cataract and a new hypothesis to explain the high prevalence of cataract in some countries. in Regnault $\mathrm{F}$, Courtois $\mathrm{Y}$ and Hockwin $\mathrm{O}$ eds Aging of the Lens. Amsterdam, Elsevier/North Holland Biomedical Press 1980: 71-80.

${ }^{13}$ Harding JJ and Rixon KC: Carbamylation of lens proteins: a possible factor in cataractogenesis in some tropical countries. Exp Eye Res 1980, 31: 567-71.

${ }^{14}$ Beswick HT and Harding JJ: Conformational changes induced in bovine lens $\alpha$-crystallin by carbamylation: relevance to cataract. Biochem J 1984, 223: 221-7.

15 Crompton M, Rixon $\mathrm{KC}$ and Harding JJ: Aspirin prevents carbamylation of soluble lens proteins and prevents cyanate-induced phase separation opacities in vitro: a possible mechanism by which aspirin could prevent cataract. Exp Eye Res 1985, 40: 297-311.

${ }^{16}$ Minassian D, Mehra VJ, Jones BR: Dehydrational crises from severe diarrhoea or heatstroke and risk of cataract. Lancet 1984, i: 751-3.

${ }^{17}$ Clayton RM, Cuthbert J, Seth J, Phillips CI, Bartholomew RS, Reid JMcK: Epidemiological and other studies in the assessment of factors contributing to cataractogenesis. Ciba Symp 1984, 106: 25-47.

${ }^{18}$ Clayton RM, Cuthbert J, Duffy J, Seth J, Phillips CI, Bartholomew RS, Reid JMcK: Some risk factors associated with cataract in SE Scotland: a pilot study. Trans Ophthalmol Soc UK 1982, 102: 331-6.

${ }^{19}$ Kahn HA, Leibowitz HM, Ganley JP, Kini MM, Colton T, Nickerson RS, Dawber TR: The Framingham Eye Study II. Association of ophthalmic pathology with single variables previously measured in the Framingham Heart Study. Am J Epidemiol 1977, 106: 33-41.

${ }^{20}$ van Heyningen $\mathrm{R}$ and Harding JJ: Do aspirin-like analgesics protect against cataract? A case-control study. Lancet 1986, i: 1111-13.

${ }^{21}$ van Heyningen $\mathrm{R}$ and Harding JJ: Risk factors for cataract: diabetes, myopia and sex. Colloq. INSERM 1986, 147: 381-5.

22 Dugmore WN and Tun K: Glucose tolerance tests in 200 patients with senile cataract. $\mathrm{Br} J$ Ophthalmol 1980, 64: 689-92. 